\title{
PENGEMBANGAN APLIKASI MOBILE LEARNING BERBASIS PROYEK PADA MATA KULIAH MEDIA PEMBELAJARAN DI STIT JEMBRANA.
}

I Wayan Santyasa ${ }^{2}$, Nyoman Parwati ${ }^{3}$, Khutum Bafaqih ${ }^{1}$

\author{
1,2,3 Program Studi Teknologi Pembelajaran \\ Universitas Pendidikan Ganesha \\ Singaraja, Indonesia
}

\author{
e-mail: \{santyasa@undiksha.ac.id ${ }^{1}$,nyoman.parwati@undiksha.ac.id ${ }^{2}$ \\ khutumb93@gmail.com ${ }^{3}$ \}
}

\begin{abstract}
Abstrak
Penelitian ini memiliki tiga tujuan yaitu: (1) untuk mendeskripsikan rancang bangun pengembangan mobile learning berbasis proyek pada mata kuliah media pembelajaran, (2) mendeskripsikan kualitas hasil validasi pengembangan mobile learning berbasis proyek yang dikembangkan menurut review para ahli dan uji coba produk pada mata kuliah Media Pembelajaran, (3) untuk mengetahui efektivitas mobile learning berbasis proyek yang dikembangkan terhadap hasil belajar mata kuliah Media Pembelajaran.

Jenis penelitian ini adalah penelitian pengembangan. Dengan menggunakan model pengembangan AM3PU3. yang terdiri dari lima tahapan utama, yaitu, (1) mentukan mata pelajaran, (2) menganalisis kebutuhan, (3) proses pengembangan draft, (4) menyusun draft pengembangan, dan (5) tinjauan ahli dan uji coba. Data yang dikumpulkan dalam penelitian ini adalah kuantitatif dan kualitatif. Metode pengumpulan data yang digunakan adalah kuesioner, dan tes tertulis. Mengacu pada metode, maka instrumen yang digunakan adalah kuesioner, dan tes. Data yang diperoleh tersebut kemudian dianalisis secara analisis deskriptif kualitatif, analisis deskriptif kuantitatif dan analisis statistik inferensial (uji-t).

Hasil penelitian ini menunjukan bahwa: (1) rancang bangun mobile learning berbasis proyek yang terdiri dari lima tahapan dari model AM3PU3. (2) kelayakan kualitas hasil validasi pengembangan mobile learning berbasis proyek terdiri dari: ahli isi $(91,35 \%)$ sangat baik, ahli media berpredikat sangat baik $(90,75 \%)$, ahli desain berpredikat sangat baik $(94 \%)$, uji coba perorangan, kelompok kecil dan uji coba lapangan berpredikat baik $(87,84 \%),(75,51 \%)$ dan $(88,82 \%)$, (3) efektivitas pengembangan mobile learning berbasis proyek menunjukkan terdapat perbedaan yang signifikan dalam penerapan pembelajaran dengan menggunakan mobile learning berbasis proyek terhadap hasil belajar Media Pembelajaran. Perhitungan hasil belajar diperoleh $\mathrm{t}$ hitung sebesar 4,256 dan harga t tabel dengan taraf signifikansi $5 \%$ adalah 2.00. Hal ini berarti nilai rerata atau mean kelompok eksperimen lebih besar dari nilai rerata kelompok kontrol, dapat dikatakan bahwa mobile learning berbasis proyek pada mata kuliah Media Pembelajaran secara efektif dapat meningkatkan hasil belajar Media Pembelajaran..
\end{abstract}

Kata-kata kunci: pengembangan, mobile learning, project based learning, model AM3PU3

\footnotetext{
Abstract

The study has three objectives: (1) to describe the design of project-based mobile learning development in the learning media course, (2) describe the quality of validation result of project-based mobile learning development developed according to expert review and product trial in the course Learning Media, (3) to know the effectiveness of project-based mobile learning developed against the learning result of Learning Media course.

This type of research is development research. Using the AM3PU3 development model. consisting of five main stages, (1) forming the subject, (2) analyzing the needs, (3) the draft development process, (4) developing the development draft, and (5) expert review and piloting. The data collected in this study is quantitative and qualitative. Data collection methods used were questionnaires, and written tests. Referring to the method, the instruments used are questionnaires, and tests. The data obtained are then analyzed by qualitative descriptive analysis, quantitative descriptive analysis and inferential statistical analysis (t-test).
} 
The results of this study show that: (1) the design of project-based mobile learning that consists of five stages of the AM3PU3 model. (2) the validity of validation quality of project-based mobile learning development consists of: content expert $(91,35 \%)$ very good, excellent predicate media expert $(90,75 \%)$, excellent predicate design expert $(94 \%),(87.84 \%),(74.51 \%)$ and $(88.82 \%),(3)$ the effectiveness of development of project-based mobile learning shows that there is a significant difference in the application of learning by using mobile learning project based on learning learning media. The calculation of learning results obtained t arithmetic amounted to 4.256 and price $t$ table with $5 \%$ significance level is 2.00 . This means that the mean value or mean of the experimental group is greater than the average value of the control group, it can be said that project-based mobile learning in the course of Learning Media can effectively improve learning outcomes Learning Media.

Keyword:Development, mobile learning, project based learning, model AM3PU3

\section{PENDAHULUAN}

Media adalah perantara atau pengantar pesan dari pengirim ke penerima pesan. Secara lebih khusus, pengertian media dalam proses belajar mengajar cenderung diartikan sebagai alat-alat grafis, fotografis, atau elektronik untuk menangkap, memproses, dan menyusun kembali informasi visual atau verbal (Kustandi 2011: 7).Oleh karena itu media berperan penting dalam proses pembelajaran.

Media pembelajaran juga diberikan sebagai mata kuliah, dengan tujuan untuk menciptakan pendidik yang mampu memilih, memproduksi, serta mengevaluasi media pembelajaran yang baik. Diharapkan dengan pemberian mata kuliah ini mahasiswa akan mampu memilih, mengembangkan, memproduksi serta dapat menilai apakah media pembelajaran yang dikembangkan dan dipilih mampu memecahkan permasalahan pembelajaran yang ada, namun terdapat permasalahan dalam pembelajaran media, hal ini terlihat pada observasi yang dilaksanakan di STIT Jembrana terjadi dilapangan pembelajaran dosen masih tradisional dengan penerapan strategi pembelajaran ceramah dan penugasan tanpa adanya praktik, apalagi dengan kurangnya sumber belajar selama proses pembelajaran membuat pembelajaran menjadi tidak terarah serta kurangnya fasilitas dalam pembelajaran membuat pembelajaran pada mata kuliah media kurang maksimal. Padahal data persentase penggunaan teknologi dalam pembelajaran mahamahasiswa di STIT Jembrana menunjukan hasil sebesar $88 \%$ diartikan bahwa sebagian besar mahasiswa telah bisa menggunakan teknologi dalam pembelajaran, selain itu mahamahasiswa STIT Jembrana sebagian besar telah memiliki smart phone yang dapat dijadikan solusi dalam pembelajaran secara online. Salah satu solusi yang dapat ditawarkan adalah dengan menciptakan suatu media pembelajaran online yang dapat digunakan dalam pembelajaran seperti mobile learning.

Mobile learning yaitu proses pemerolehan pengetahuan dan keterampilan melalui penggunaan teknologi mobile, dimana saja, kapan saja, yang menghasilkan suatu perubahan perilaku (Nasution, 2016).

Melihat permasalahan ini dirasa perlu memanfaatkan situasi dengan maraknya perkembangan smartphone maka akan dikembangkan mobile learning berbasis proyek dalam proses pembelajaran Media di STIT Jembrana semester IV.

Berdasarkan latar belakang tersebut, maka permasalahan yang 
dijadikan dasar pada penelitian pengembangan ini sebagai berikut.

(1) Bagaimana rancang bangun dan pengembangan aplikasi mobile learning berbasis proyek dilakukan untuk mata kuliah media pembelajaran di STIT Jembrana?, (2) Bagaimana respon para ahli, dosen mata kuliah dan mahamahasiswa terhadap aplikasi mobile learning berbasis proyek dilakukan untuk mata kuliah media pembelajaran di STIT Jembrana? (3) Bagaimanakah efektivitas aplikasi mobile learning berbasis proyek dilakukan untuk mata kuliah media pembelajaran di STIT Jembrana?.

Tujuan penelitian diantaranya: Secara Umum Menghasilkan produk pembelajaran berupa aplikasi mobile learning berbasis proyek yang valid, praktis, dan efektif sehingga memiliki keunggulan dan kelayakan pakai.

Secara Khusus 1. Menjelaskan rancang bangun dan aplikasi mobile learning berbasis proyek pada mata kuliah media pembelajaran di STIT Jembrana. 2. Mendeskripsikan validitas aplikasi mobile learning berbasis proyek meliputi validitas isi, desain pembelajaran, dan media. 3 . Mendeskripsikan kepraktisan aplikasi mobile learning berbasis berbasis proyek berdasarkan kemudahan pengoperasian dan kemenarikan antarmuka. 4. Mendeskripsikan keefektifan aplikasi mobile learning berbasis proyek melalui uji pra eksperimen.

\section{METODE PENELITIAN}

$\begin{array}{ccc}\text { Model } & \text { penelitian yang } \\ \text { digunakan } & \text { adalah } & \text { model }\end{array}$ pengembangan AM3PU3.

Model pengembangan AM3PU3 dimulai dari analisis kebutuhan yang ada dilapangan, mengkaji kebutuhan tersebut melalui teori dan keadaan yang ada dilapangan sehingga didapatkan masalah yang relevan serta dicari juga bagaimana cara penyelesaian masalah tersebut, kemudian setelah masalah dikaji serta ditemukan penyelesaiannya maka dipilih desain pengembangan yang sesuai, kemudian mulailah tahap pengembangan, validasi produk, revisi hingga didapatkan produk akhir.

Prosedur penelitian dengan model pengembangan AM3PU3 terdiri dari lima tahapan 1. Menentukan Mata Pelajaran, 2. Menganalisis Kebutuhan, 3. Proses Pengembangan Draft, 4. Menyususn Draft Pengembangan, 5. Tinjauan ahli dan uji coba. Penelitian ini menggunakan dua metode pengumpulan data untuk menjawab permasalahan mengenai rancang bangun pengembangan media mobile learning berbasis proyek, validitas hasil pengembangan mobile learning berbasis proyek, dan efektivitas penggunaan mobile learning berbasis proyek terhadap hasil belajar mahamahasiswa.

Guna menjawab permasalahan mengenai tiga permasalahan diatas digunakan dua metode pengumpulan data kuisioner, dan tes tertulis

Metode kuesioner adalah daftar pertanyaan yang diberikan kepada orang lain dengan maksud agar orang yang diberi kuesioner bersedia memberikan respons sesuai dengan permintaan pengguna (Arikunto, 2005:128).

Metode tes yang digunakan pada penelitian ini adalah tes hasil belajar yaitu tes esai. Tes esai digunakan pada uji efektivitas produk hasil belajar mahasiswa.

Dalam penelitian pengembangan ini digunakan tiga teknik analisis data, yaitu teknik analisis deskriptif kualitatif, analisis statistik deskriptif kuantitatif, dan 
analisis statistik inferensial (uji t berkorelasi).

Teknik analisis data deskriptif kualitatif. Teknik analisis ini digunakan untuk mengolah data yang diperoleh melalui angket dalam bentuk deskriptif persentase. (Santyasa, 2015). Rumus yang digunakan untuk menghitung persentase dari masing-masing subyek adalah :

Persentase $=$

$\frac{\sum(\text { Jawaban } \times \text { bobot tiap pilihan })}{\mathrm{n} \times \text { bobot tertinggi }} \times 100 \%$

Keterangan:

$\Sigma=$ jumlah $\mathrm{n}=$ jumlah seluruh item angket

Selanjutnya, untuk menghitung persentase keseluruhan subyek digunakan rumus:

Persentase $=\mathrm{F}: \mathrm{N}$

Keterangan:

$\mathrm{F}=$ jumlah persentase keseluruhan subyek

$\mathrm{N}$ = banyak subyek

Untuk dapat memberikan makna dan pengambilan keputusan digunakan ketetapan sebagai berikut.

Tabel 1.1 Konversi Tingkat Pencapaian Skala 5

\begin{tabular}{|c|l|l|}
\hline Tingkat Pencapaian (\%) & \multicolumn{1}{|c|}{ Kualifikasi } & \multicolumn{1}{c|}{ Keterangan } \\
\hline $90-100$ & Sangat Baik & Tidak perlu direvisi \\
\hline $75-89$ & Baik & Direvisi seperlunya \\
\hline $65-74$ & Cukup & Cukup Banyak Direvisi \\
\hline $55-64$ & Kurang & Banyak Direvisi \\
\hline $0-54$ & Sangat Kurang & Direvisi Total \\
\hline
\end{tabular}

Sumber: Tegeh, Jampel dan Pudjwan (2014)

Teknik analisis deskriptif kualitatif ini digunakan untuk mengolah data hasil review ahli isi, ahli desain pembelajaran, ahli media pembelajaran, dan mahamahasiswa.

Teknik analisis data ini dilakukan dengan mengelompokkan informasiinformasi dari data kualitatif yang berupa masukan, tanggapan, kritik dan saran perbaikan yang terdapat pada angket dan hasil wawancara. Hasil analisis ini kemudian digunakan untuk merevisi produk yang dikembangkan.

Analisis statistik inferensial digunakan untuk mengetahui tingkat efetivitas produk terhadap hasil belajar mahamahasiswa STIT Jembrana Semester IV Jurusan PAI, sebelum dan sesudah menggunakan produk pengembangan mobile learning berbasis proyek dalam pembelajaran. Data uji coba kelompok sasaran dikumpulkan dengan menggunakan pre-test dan post-test terhadap materi pokok yang diuji cobakan.

Hasil pre-test dan post-test kemudian dianalisis menggunakan uji-t untuk mengetahui perbedaan antara hasil pre-test dan post-test. Sebelum melakukan uji hipotesis (uji-t berkorelasi) dilakukan uji prasyarat (normalitas dan homogenitas).Rumus untuk 
menghitung uji prasyarat dan uji hipotesis (uji-t berkorelasi) adalah sebagai berikut.

(a) Uji Prasyarat

Pengujian hipotesis dilakukan dengan analisis uji $\mathrm{t}$ berkorelasi. Analisis uji $t$ berkorelasi memerlukan beberapa persyaratan analisis antara lain:

1. Uji Normalitas

Uji normalitas dilakukan untuk mengetahui apakah sebaran skor pada setiap variabel berdistribusi normal atau tidak, untuk itu dapat digunakan rumus Chi-Kuadrat. Adapun rumusnya sebagai berikut.

$$
x^{2}=\sum\left[\frac{(f o-f e)^{2}}{f e}\right]
$$

(Koyan, 2012:90)

Keterangan:

$\mathrm{x}^{2}=$ chi-kuadrat

fo $=$ frekuensi observasi

$\mathrm{fe}=$ frekuensi harapan

Kriteria pengujian: data berdistribusi normal jika $x^{2}$ hitung $<x^{2}$ tabel pada taraf signifikansi $\alpha=0,05$ dengan derajat kebebasan k-1.

\section{Uji Homogenitas}

$\begin{array}{ccc}\text { Uji } & \text { homogenitas dilakukan } \\ \text { untuk } & \text { mencari } & \text { tingkat }\end{array}$ kehomogenan secara dua pihak yang diambil dari kelompokkelompok terpisah dari satu populasi yaitu kelompok kontrol dan kelompok eksperimen. Untuk menguji homogenitas varians untuk kedua kelompok digunakan uji Fisher $(F)$, sebagai berikut.

$$
F=\frac{\text { Varians terbesar }}{\text { Varians terkecil }}
$$

Kriteria pengujian $\mathrm{H} \neg 0$ diterima jika Fhitung < Ftabel yang berarti sampel homogen.Uji dilakukan pada taraf signifikan $5 \%$ dengan derajat kebebasan untuk pembilang $\mathrm{n} 1-1$ dan derajat kebebasan untuk penyebut n2 - 1 .

(b) Uji Hipotesis

Teknik analisis yang digunakan untuk pengujian hipotesis adalah teknik analisis uji $\mathrm{t}$ berkorelasi atau dependen. Dasar penggunaan teknik $u j i ~ t$ berkorelasi ini adalah menggunakan dua perlakuan yang berbeda terhadap satu sampel. Pada penelitian ini akan menguji perbedaan hasil belajar Bahasa Indonesia sebelum dan sesudah menggunakan mobile learning berbasis proyek terhadap satu kelompok. Rumus untuk uji-t berkorelasi adalah sebagai berikut.

$$
\begin{aligned}
& t \\
& =\frac{\overline{x_{1}}-\overline{x_{2}}}{\sqrt{\frac{\left(n_{1}-1\right) s_{1}{ }^{2}+\left(n_{2}-1\right) s_{2}{ }^{2}}{n_{1}+n_{2}-2}\left(\frac{1}{n_{1}}\right)+\left(\frac{1}{n_{2}}\right)}} \\
& \text { (Koyan, 2012:29) } \\
& \text { Keterangan: } \\
& \mathrm{t}=\mathrm{uji} \mathrm{t} \text { tidak berkorelasi } \\
& \overline{x_{1}}=\text { rata-rata sampel } 1 \text { (kelompok } \\
& \mathrm{s}_{1}{ }^{2}=\text { varians sampel } 1
\end{aligned}
$$ 2(kelompok tidak menggunakan mobile learning berbasis proyek )




$$
\begin{array}{rlr}
\mathrm{n}_{1}= & \begin{array}{l}
\text { besarnya } \\
\text { (kelompok sampel }
\end{array} \\
& \text { mobile learning } 1 \\
& \text { proyek ) } \\
\mathrm{n}_{2}= & \text { besarnya } & \text { berbasis } \\
& \text { (kelompok sampel } & 2 \\
& \text { menggunakan } & \text { tidak } \\
& \text { learning berbasis proyek ) }
\end{array}
$$

Hasil uji coba dibandingkan ttabel dengan taraf signifikan 0,05 $(5 \%)$ untuk mengetahui apakah ada perbedaan antara sebelum dan sesudah menggunakan mobile learning berbasis proyek.

$\mathrm{H}_{0}$ : Tidak terdapat perbedaan hasil belajar setelah menggunakan aplikasi mobile learning berbasis proyek lebih tinggi dengan mencapai kreteria keberhasilan.

$\mathrm{H}_{1}$ : Terdapat perbedaan hasil belajar setelah menggunakan aplikasi mobile learning berbasis proyek lebih tinggi dengan mencapai kreteria keberhasilan.

\section{Hipotesis Statistiknya:}

$\mathrm{H} 0: \mu 1=\mu 2$

$\mathrm{H} 1: \mu 1 \neq \mu 2$

\section{Keputusan:}

Bila thitung $\geq \mathrm{t}$ tabel maka $\mathrm{H}_{0}$ ditolak dan $\mathrm{H}_{1}$ diterima.

Bila thitung $\leq$ dari tabel, maka $\mathrm{H}_{0}$ diterima dan $\mathrm{H}_{1}$ ditolak.

\section{HASIL DAN PEMBAHASAN}

Hasil penelitian dibahas lima hal pokok, yaitu (1) Rancang bangun Mobile learning berbasis proyek , (2) Kualitas hasil validasi pengembangan mobile learning berbasis proyek ,(3) Revisi pengembangan produk, (4) Uji prasyarat analisis data dan (5) Uji hipotesis.

Rancang Bangun mobile learning berbasis proyek dilakukan dengan analisis materi yang akan digunakan, pembuatan flowchart dan storyboard. Storyboard merupakan gambaran dari setiap tampilan dan pengaturan tata letak konten pada mobile learning berbasis proyek , sehingga memudahkan penulis dalam penyusunan setiap tampilan dalam mobile learning berbasis proyek .

Produksi mobile learning berbasis proyek mulai dirancang berdasarkan storyboard yang dibuat. Mobile learning berbasis proyek yang dikembangkan menggunakan menggunakan perangkat lunak antar muka (user interface) software adobe phonegap dengan bantuan adobe photoshop sebagai pengelola gambarnya serta adobe dreamweaver sebagai pengelola website. Mobile learning yang dikembangkan nanti berupa aplikasi yang akan terinstal pada smart phone yang telah dimiliki mahasiswa dengan versi sistem operasi minimal 2.2 (froyer). Pengembangan aplikasi mobile learning dikembangkan dan dievaluasi berdasarkan konten media pembelajaran yang berupa teks, gambar, dan video.

Dalam proses pengembangannya, mobile learning berbasis proyek disesuaikan dengan storyboard dan model pembelajaran project based learning sebagai landasan pembelajarannya. Selain itu pembuatan produk ini juga mengacu pada Rencana Mutu Pembelajaran. Sehingga mobile learning berbasis proyek yang dikembangkan benarbenar disesuaikan dengan karakteristik mahasiswa dan pembelajaran di STIT Jembrana.

Dalam mobile learning berbasis proyek akan disajikan tujuh sub 
pembahasan harus dipahami mahasiswa yang dimudahkan dengan adanya kesimpulan akan materi yang diajarkan, selain itu pula mobile learning berbasis proyek ini dilengkapi dengan soal proyek yang akan membuat mahasiswa lebih memahami materi lebih jauh. Diharapkan dengan hal ini membuat mahasiswa lebih mengerti akan materi yang dijelaskan.

Kualitas hasil pengembangan produk. Dalam hal ini akan dipaparkan enam hal pokok, yaitu Uji Ahli Isi Mata Pelajaran, Uji Ahli Desain Pembelajaran, Uji Ahli Media Pembelajaran, Uji Coba Perorangan, Uji Coba Kelompok Kecil, dan Uji Coba Lapangan. Keenam data tersebut akan disajikan secara berturut-turut sesuai dengan hasil yang diperoleh dari masing-masing tahapan uji coba.

Dua Uji Ahli Isi mendapatkan presentase $91,35 \%$ berada pada kualifikasi sangat baik. Dua Uji Ahli Media mendapatkan presentase $90,75 \%$ berada pada kualifikasi sangat baik. Dua Uji ahli desain mendapatkan persentase tingkat pencapaian $94 \%$ berada pada kualifikasi sangat baik.

Uji coba perorangan ini adalah mahasiswa semester IV STIT Jembrana sebanyak 3 (tiga) mahasiswa. Mahasiswa tersebut terdiri dari satu orang mahasiswa dengan prestasi belajar tinggi, satu orang mahasiswa dengan prestasi belajar sedang dan satu orang mahasiswa dengan prestasi belajar rendah. Rerata persentase tingkat pencapaian $87,84 \%$ berada pada kualifikasi baik. Dan perlu mendapatkan revisi sesuai dengan saran dari mahasiswa.

Uji coba kelompok kecil, subjek coba dalam penelitian ini adalah mahasiswa semester IV STIT Jembrana sebanyak 6 (Enam) mahasiswa. Mahasiswa tersebut terdiri dari dua orang mahasiswa dengan prestasi belajar tinggi, dua orang mahasiswa dengan prestasi belajar sedang dan dua orang mahasiswa dengan prestasi belajar rendah. Rerata persentase tingkat pencapaian $75,51 \%$ berada pada kualifikasi baik. Dan pada uji ini media yang digunakan tidak pelu dilakukan revisi.

Uji coba lapangan dilakukan kepada 28 orang mahasiswa Semester IV sebagai kelas eksperimen, persentase tingkat pencapaian 88,82 \% berada pada kualifikasi baik.

Revisi pengembangan produk. Dalam pengembangan produk mobile learning berbasis proyek ini melalui enam tahapan yaitu (1) ahli isi mata pelajaran, (2) ahli media pembelajaran, (3) ahli desain pembelajaran, (4) uji coba perorangan, (5) uji coba kelompok kecil, (6) uji coba lapangan. Dalam ke enam tahapan revisi tersebut, tidak ada revisi yang cukup besar yang perlu direvisi namun hanya ada beberapa masukan dan saran dari para ahli dan subjek uji coba.

Prasyarat Analisis Data. Sebelum dilakukan pengujian hipotesis mobile learning berbasis proyek dengan menggunakan uji-t, sebelumnya perlu dilakukan pengujian prasyarat analisis data. Uji prasyarat analisis meliputi uji normalitas sebaran data yang dikenakan pada kedua kelompok dan uji homogenitas varians dari hasil pretest dan postest yang telah dilakukan. Adapun penjelasan dari hal tersebut adalah sebagai berikut.

Uji normalitas sebaran data dilakukan untuk menyajikan bahwa sampel benar-benar berasal dari populasi yang berdistribusi normal. Uji normalitas data dilakukan terhadap skor perolehan (gain score) yang ternormalisasikan dari hasil pretest 
dan posttest kelompok eksperimen maupun kelompok kontrol.

Berdasarkan perhitungan ditemukan Chi-Kuadrat hitung ( $X^{2}$ hitung) $=-21,7819$ harga selanjutnya dibandingkan dengan Chi-Kuadrat tabel ( $X^{2}$ tabel), dengan $\mathrm{dk}$ (derajat kebebasan) $6-2-1=2$. Bila dk 3 taraf signifikan 5\% maka harga $X^{2}$ tabel $=$ 11.3, karena $X^{2}$ hitung $<X^{2}$ tabel $(-$ $21,7819<11.3)$, maka dapat dikatakan bahwa data hasil belajar media pembelajaran kelompok eksperimen berdistribusi normal. Sedangkan, untuk uji normalitas hasil pretest dan posttest kelompok kontrol, berdasarkan perhitungan ditemukan harga Chi-Kuadrat hitung ( $x^{2}$ hitung $)=-$ 19.616 harga tersebut selanjutnya dibandingkan dengan harga ChiKuadrat tabel ( $\mathrm{X}^{2}$ tabel), dengan $\mathrm{dk}$ (derajat kebebasan) 6-2-1 = 3. Bila dk 3 dan taraf signifikan $5 \%$ maka harga $X^{2}$ tabel $=11,3$, karena $x^{2}$ hitung $<X^{2}$ tabel $(-19,616<11,3)$, maka dapat dikatakan bahwa data hasil belajar Media Pembelajaran kelompok kontrol berdistribusi normal. Dengan demikian semua data skor hasil belajar media mahasiswa berdistribusi normal.

Uji Homogenitas. Homogenitas data dianalisis dengan uji- $F$, dengan kriteria data homogen jika $F_{\text {hitung }} \leq \mathrm{F}_{\text {tabel }}$, dan data tidak homogen jika $\mathrm{F}_{\text {hitung }} \geq \mathrm{F}_{\text {tabel }}$. Berdasarkan hasil pengujian diperoleh $F_{\text {hitung }}=1.91$ sedangkan $\mathrm{F}_{\text {tabel }}=1.88$ dengan taraf signifikansi $5 \%$. Jadi dapat disimpulkan $F_{\text {hitung }}<F_{\text {tabel }}$ sehingga kedua data tersebut memiliki varians yang homogen.

Uji Hipotesis. Berdasarkan hasil pengujian normalitas dan homogenitas diperoleh bahwa data yang didapatkan dari kelompok eksperimen dan kelompok kontrol berdistribusi normal dan homogen. Berdasarkan hal tersebut, maka dilakukan uji hipotesis dengan menggunakan rumus polled varians, kriteria pengujian adalah tolak $\mathrm{H}_{0}$ jika thitung $>$ tabel dengan derajad kebebasan (dk) $n_{1}+n_{2}-2$ dan $a=$ $5 \%$.Berdasarkan hasil uji-t diperoleh thitung $=4,256$ dan tabel $=2.00$ untuk db $=54$ dari taraf signifikansi $5 \%$. Hal ini berarti thitung $>$ ttabel, sehingga $\mathrm{H}_{0}$ ditolak dan $\mathrm{H}_{1}$ diterima. Berdasarkan kriteria pengujian, $\mathrm{H}_{0}$ ditolak dan $\mathrm{H}_{1}$ diterima yang artinya terdapat perbedaan yang signifikan dalam penerapan pembelajaran dengan menggunakan mobile learning berbasis proyek .

\section{SIMPULAN DAN SARAN}

Rancang bangun pengembangan mobile learning berbasis proyek untuk mata kuliah Media Pembelajaran menggunakan model pengembangan AM3PU3. Dengan lima tahapan utama (1) mentukan mata pelajaran, (2) menganalisis kebutuhan, (3) proses pengembangan draft, (4) menyusun draft pengembangan, dan (5) tinjauan ahli dan uji coba.

Validitas hasil pengembangan mobile learning berbasis proyek untuk mata kuliah Media Pembelajaran telah dilakukan dengan metode kuesioner. Dengan enam orang ahli dua orang ahli isi, dua orang ahli media pembelajaran dan dua orang ahli desain pembelajaran. Rata-rata yang diberikan oleh dua orang ahli isi adalah pada kualifikasi sangat baik $(91,35 \%)$. Menurut dua orang ahli media pembelajaran, validitas mobile learning berbasis proyek berada pada kualifikasi sangat baik (90,75\%). Menurut dua ahli desain pembelajaran, validitas mobile learning berbasis proyek berada pada kualifikasi sangat baik (94\%). Pada tahap uji coba perorangan, mobile learning berbasis proyek yang diuji berada pada tingkat pencapaian $87,84 \%$ dan berada pada kualifikasi baik. Pada tahap uji coba 
kelompok kecil berada pada tingkat pencapaian $74,51 \%$ dan berada pada kualifikasi baik, sehingga media yang divalidasikan layak digunakan pada aspek validasi kelompok kecil. Pada tahap uji coba lapangan dilaksanakan, angket hasil uji coba lapangan yang berada pada kualifikasi baik yaitu $88,82 \%$.

Efektivitas pengembangan mobile learning berbasis proyek telah dilakukan dengan metode tes. Ratarata nilai dinormalisasi kelompok eksperimen adalah 95,357 dan ratarata nilai dinormalisasi kelompok kontrol adalah 93,32. Setelah dilakukan penghitungan secara manual diperoleh hasil thitung sebesar 4,256 . Kemudian harga thitung dibandingkan dengan harga ttabel dengan $\mathrm{db}=\mathrm{n} 1+\mathrm{n} 2-2=28+28-2$ $=54$. Harga tabel untuk db 54 dan dengan taraf signifikansi $5 \%(\alpha=0,05)$ adalah 2.00. Dengan demikian, harga thitung lebih besar daripada harga trabel sehingga $\mathrm{H}_{0}$ ditolak dan $\mathrm{H}_{1}$ diterima. Ini berarti, terdapat perbedaan hasil belajar setelah menggunakan aplikasi mobile learning berbasis proyek.

Saran-saran yang disampaikan berkenaan dengan pengembangan mobile learning berbasis proyek pada mata kuliah Media Pembelajaran ini dikelompokkan menjadi empat, yaitu (1) kepada mahasiswa, (2) kepada dosen, (3) Lembaga penelitian, dan (4) kepada peneliti lain.

1. Kepada Mahasiswa

Mahasiswa disarankan dapat menggunakan mobile learning berbasis proyek secara optimal. Sehingga media yang telah dikembangkan dapat meningkatkan kemampuan mahasiswa utamanya dalam mata kuliah media pembelajaran.

2. Kepada Dosen

$\begin{array}{lrr}\text { Dosen disarankan } & \text { untuk } \\ \text { menggunakan } & \text { mobile learning }\end{array}$

berbasis proyek, dalam pembelajaran agar memudahkan dosen dalam mengajar dan mendapatkan hasil yang sesuai dengan tujuan pembelajaran. Selain itu, kepada dosen disarankan agar mencari sumber-sumber belajar lainnya agar mahasiswa dapat belajar dengan maksimal dan tidak hanya melakukan pembelajaran secara monoton.

3. Lembaga Penelitian

Lembaga atau Kampus dilaksanakannya penelitian disarankan untuk mengambil kebijakan untuk mengadakan media-media baru seperti LCD, atau laptop yang memadai dan akan menjembatani antara mahasiswa dengan materi yang disampaikan. Selain itu lembaga penelitian juga diharapkan mengambil kebijakan untuk melakukan pengadaan fasilitas pendukung pembelajaran.

\section{Kepada Peneliti Lain}

Bagi peneliti lain diharapkan penelitian ini akan dapat dijadikan referensi dalam melakukan penelitian sejenis yang bersifat pengembangan lebih lanjut dan luas.

\section{UCAPAN TERIMA KASIH}

Dalam proses pembuatan Tesis ini, sangat banyak mendapat bantuan dari berbagai pihak. Oleh karena itu, pada kesempatan ini diucapkan terimakasih yang tulus dan sebesarbesarnya kepada yang terhormat:

1. Prof. I Wayan Santyasa,M.Si selaku Ketua Prodi Teknologi Pembelajaran dan Pembimbing I yang telah banyak memberikan masukan, saran dan motivasi selama perkuliahan.

2. Dr. Ni Nyoman Parwati, M.Pd, selaku pembimbing II yang 
telah banyak memberikan masukan, arahan, petunjuk, dan saran dalam pelaksanaan penelitian.

3. Almarhum Dr. I Made Kirna, M.Si, selaku mantan Ketua Prodi Teknologi Pembelajaran yang membimbing, memotivasi, dan membina kami.

4. Dr. Ni Ketut Agustini, S.Si., M.Si, selaku Sekretaris Prodi Teknologi Pembelajaran yang membimbing, memotivasi, dan membina kami

5. Dosen program studi Teknologi Pembelajaran, yang memberikan ilmu serta selalu membimbing selama perkuliahan.

6. Teman-teman Mahasiswa Program Studi Teknologi Pembelajaran dan seluruh pihak yang tidak bisa disebutkan satu persatu yang telah memberikan bantuan, saran, dan dorongan dalam penelitian.

\section{DAFTAR PUSTAKA}

Koyan, I W. 2012. Statistik Pendidikan Teknik Analisis Data Kuantitatif. Singaraja: Undiksha.

Nasution, M. 2016. Strategi pembelajaran efektif berbasis mobile learning pada sekolah dasar. Jurnal iqra'.10(1).1-14. Terdapat pada http://library. iainsu.ac.id/journal. Diakses 8 September 2016.

Santyasa, I. W. 2015. Pendekatan kuantitatif dalam penelitian mipa dan pendidikan MIPA.
Makalah (tidak diterbitkan), disajikan dalam Seminar akademik fakultas MIPA Undiksha, 25 Nopember 2015 di Singaraja

Tegeh, I M \& I Made Kirna. 2010. Metode Penelitian Pengembangan Pendidikan. Buku Ajar(tidak diterbitkan). Singaraja: Undiksha. 